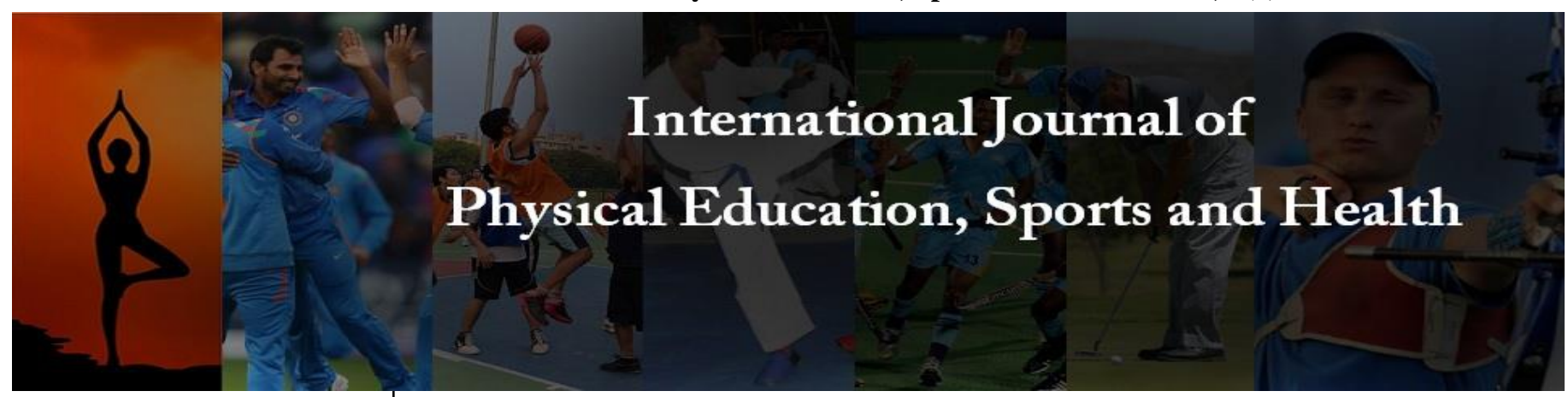

P-ISSN: 2394-1685

E-ISSN: 2394-1693

Impact Factor (ISRA): 5.38

IJPESH 2021; 8(5): 215-217

(C) 2021 IJPESH

www.kheljournal.com

Received: 06-07-2021

Accepted: 13-08-2021

Dr. Sagar Kulkarni

Assistant Professor, M.S.M.'s

College of Physical Education,

Aurangabad, Maharashtra, India
Corresponding Author: Dr. Sagar Kulkarni

Assistant Professor, M.S.M.'s College of Physical Education, Aurangabad, Maharashtra, India

\section{Comparative study of strength and flexibility of gymnastics and Mallakhamb players of age 11 and 12 years}

\section{Dr. Sagar Kulkarni}

DOI: https://doi.org/10.22271/kheljournal.2021.v8.i5d.2260

\section{Abstract}

Basic Gymnastics and Mallakhamb both competitive sporting events are being used as activities to develop fitness components since very long time. Gymnastics involves more space, equipments and variety of movements whereas in Mallakhamb various yogic postures and movements are performed only on a single wooden pole which requires very less space and some mats for safety. The researcher has carried comparative study of developments of motor components strength and flexibility. For the study total 60 novice players (30 from each discipline) of age 11 and 12 of each discipline were selected as samples from five various Cenetrs within state of Maharashtra. It was hypothesized that there will be no significant difference in strength and flexibility in Gymnastics and Mallakhamb players of age 11 and 12 years. Medicine ball throw and bend and reach tests were used as standardized tests to collect data. Mean standard deviation and t- test was applied for statistical findings and draw conclusions. From the statistical treatments it was concluded that there was a significant difference in strength and flexibility in Gymnastics and Mallakhamb players. Hence hypotheses were rejected.

Keywords: Strength, flexibility, gymnastics, Mallakhamb, novice players

\section{Introduction}

As we know basic gymnastics and mallakhamb exercises help in developing physical fitness and motor abilities, an exclusive study of both forms of exercises is necessary due to some circumstances. Basic gymnastics requires various equipments like floor exercises, parallel bars, roman rings, high bar, table vault, trampoline, spring boards, safety mats etc. The availability of various equipments leads to requirement of more space and more funds to purchase the equipment. Not every school or institution can afford to invest in large for basic gymnastics too. On the other side mallakhamb is a traditional Indian form of exercise now emerged as a sporting event too. Mallakhamb as an equipment is just a wooden pole fixed in ground and requires some mats for safety. It is clear that both basic exercises tend to develop physical fitness and motor abilities. But it will be more beneficial if a comparative study and analysis of mallkhamb and gymnastics players is carried out in order to reveal the developments in motor abilities in mallakhamb and gymnastics players undergoing regular training of the respective games.

\section{Significance of the study}

The study may reveal development in strength and flexibility in gymnasts and mallakhamb players of 11 and 12 years.

\section{Scope of the research}

Development of strength and flexibility were considered for the study. The gymnasts and mallakhamb players from various centres within Maharashtra state were considered for the study. Only gymnasts and mallakhmab players aged between 11 and 12 years were considered for the study.

\section{Statement of the problem}

"A comparative study of strength and flexibility of Gymnastics and Mallakhamb Players of age 11 and 12 years." 


\section{Objectives of the study}

To compare the development of strength and flexibility in gymnastics and mallakhamb players of age 11 and 12 years.

\section{Limitations of the study}

Any bias that may exist due to insincere response from the subject. Difference in intellectual and cognitive level of the subjects. Individual physical abilities of the participating subjects. Response from the samples.

\section{Delimitation of the study}

The study is delimited to boys only.

The study is delimited to only five training centers only.

\section{Hypotheses}

Ho1: There will be no significant difference in strength of Gymnastics and Mallakhamb players of age 11 and 12 years.

Ho2: There will be no significant difference in strength of Gymnastics and Mallakhamb players of age 11 and 12 years.

\section{Materials and Methods \\ Methodology}

Sample: For the present study survey method is applied. Total 60 samples (30 each from gymnastics and mallakhamb) were randomly selected from various training centers within the state of Maharashtra.

\section{Tools and Means of collection of data}

1. Personal data bank used to collect the information of an individual. Medicine ball throw test for strength and sit and reach test for test of flexibility was used as standardized test to collect the data.

2. Equipment: $1 \mathrm{~kg}$. Medicine ball, Sit and reach test box, measuring tape, marking chalk.

\section{Procedure}

Medicine ball throw test: The sample was asked to sit in split position with back touching to a wall. The sample was asked to throw the ball by bending it towards chest and extending to throw in angle of approximately 45 degree. The sample was given three attempts and best throw was recorded.

Bend and reach test: The sample was asked to sit in long sitting position with legs touching the stipulated position on the sit and reach box. The subject was asked to bend forward stretching his arms together sliding over the marked scale on the sit and reach test box with legs straight. The performance was marked on the scale where hands reach to the maximum in forward bend position.

\section{Scoring}

Each sample was given three trials and the best performance measured and recorded. The recorded distance was considered as score of the subject.

\section{Statistical means}

Mean, standard deviation and t- test was applied.

\section{Results and discussion}

Analysis and Interpretation of Data:

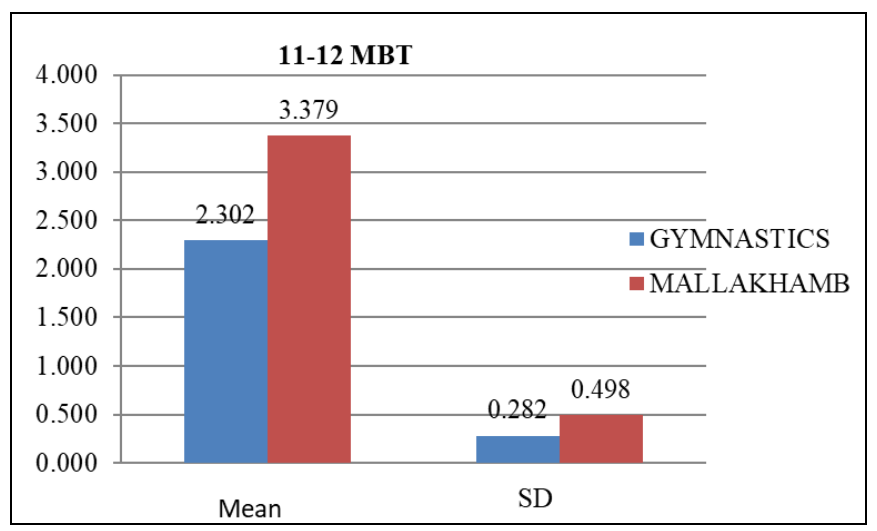

Graph 1: Reflecting the facts regarding the mean and standard deviation of the test of Medicine Ball Throw conducted on the players of the Gymnastics and Mallakhamb of the age ranging from 11 to 12 years.

Above Graph 1 depicts the following facts regarding the average of tests of Medicine Ball Throw conducted on the players of the Gymnastics and Mallakhamb of the age ranging from 11 to 12 years.

1. Mean score of the Gymnastics players is 2.302 with standard deviation of 0.282

2. Mean score of the Mallakhamb players is 3.379 with standard deviation of 0.498

3. The mean difference among the Gymnastics and Mallakhamb players is -1.077

4. T-test was used at 0.05 level of significance. The obtained t- value -13.313 at 98 degree of freedom was found significant at 0.05 level of significance further confirms that the mean difference is significant.

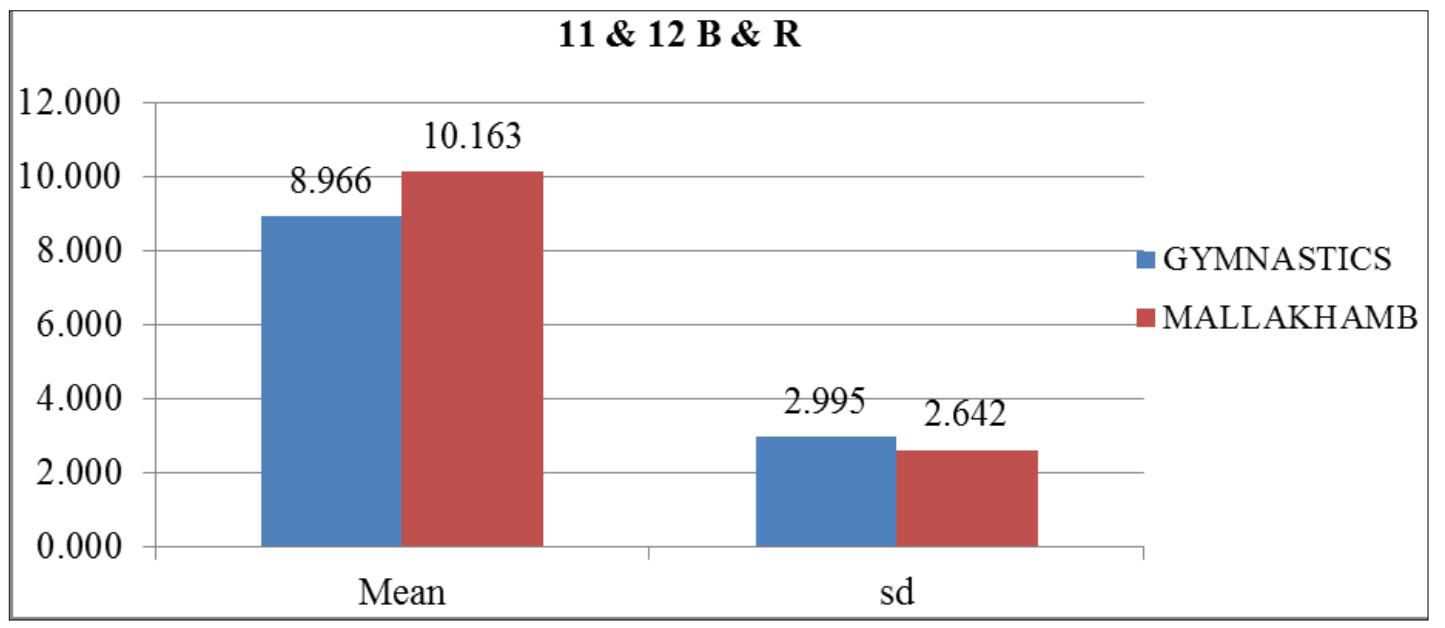

Graph 2: Reflecting the facts regarding the mean and standard deviation of the test of bend and reach conducted on the players of the Gymnastics and Mallakhamb of the age ranging between 11 and 12 years. 
Above Graph 2 depicts the following facts regarding the average of test of bend and reach conducted on the players of the Gymnastics and Mallakhamb of the age ranging between 11 and 12 years.

1. Mean score of the Gymnastics players is 8.966 with standard deviation of 2.995

2. Mean score of the Mallakhamb players is 10.163 with standard deviation of 2.642

3. The mean difference among the Gymnastics and Mallakhamb players is -3.50200

4. T-test was used at 0.05 level of significance. The obtained t- value -6.359 at 98 degree of freedom was found significant at 0.05 level of significance further confirms that the mean difference is significant.

\section{Conclusion}

From the interpretations of above graphs it is concluded that there is significant difference in strength and flexibility of Gymnastics and Mallakhamb players aged 11 and 12 years. The strength and flexibility in Mallakhamb players was found more than in Gymnasts of age group 11 and 12 years.

\section{Test of Hypotheses}

1. As the first hypothesis states that there will be no significant difference in strength of Gymnastics and Mallakhamb players aged 11 and 12 years. As the mean difference among Gymnastics and Mallakhamb players is significant the first hypothesis is rejected on the basis of findings.

2. As the second hypothesis states that there will be no significant difference in flexibility of Gymnastics and Mallakhamb players aged 11 and 12 years. As the mean difference among Gymnastics and Mallakhamb players is significant the first hypothesis is rejected on the basis of findings.

\section{Researches}

1. Saurabh Trikha. 'Comparative study of general motor abilities of handball and hockey players'. IJPNPE 2017;2(2):174-175

2. Sunil Dudhale B. Bhate. 'Comparative Study Of PsychoMotor Abilities Of Tribal and Non-tribal Gymnasts'. Research Journal of Physical Education Sci. February 2015;3(2):9-10

3. Naseer Alwasif. 'The effect of a sports program on the motor abilities of preschool children' Theories \& Applications, the International Edition 2013;3(3):67-77.

4. Magdalena Rokicka-Hebel. 'Corrective gymnastics and motor skills of five and six year old children' Baltic journal of health and physical activity 2014;6(2):114-126

5. Amandeep Singh, Vishaw Gaurav, Sandeep 'Study of selected respiratory indices among indigenous game players. Golden research thoughts 2014;4(4):1-5

6. Sourabh Trikha, Dr. Ashok Kumar Sharma. 'Comparative study of Motor Abilities and Psychological Variable of Different Game Players 2013.

7. Mahdi Fahimi, Mohamad Ali Aslankhan, The effect of four motor programs on motor proficiency in 7-9 years old boys'. Middle-East journal of Scientific Research. 2013;13(11):1526-1532

8. Ufuk Alpkaya The effect of basic gymnastics training integrated with physical education courses on selected motor performance variables.' Academic Journals 2013;8(7):317-319

9. Shanti Sharma, Dr. Alok Mishara, Jaya Sharma. 'History and benefits of Mallakhamb' 2010

10. Basford L. 'The science of movement' London Sampson low 1966.

11. Beoer MR. 'Efficiency of human movement', P.A: W. B. Saunders 1973.

12. Tony Smith. 'Gymnastics, a mechanical understanding' Hodder and Stought publication 1982.

13. Peter Aykro. 'skills and tactics of gymnastics', Acro publishing Inc 1980.

14. Phyllis Cooper, Milan Trnk. 'Teaching gymnastics skills to men and women.' Sheley enterprises, New Delhi 1982

15. Dr. Devendra Balayan. 'Gymnastics'. New dnyan offset printers and publishers, New Delhi 2007.

16. Laxmikant Pandeya. 'Bhartiya khelo ki mimansa, Metropolitan book company, New Delhi 1982.

17. www.brianmac.co.uk

18. www.wikipedia.org

19. www.topendsports.com 